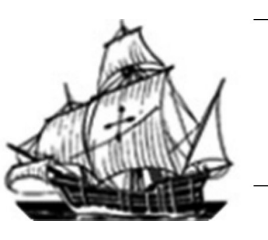

Nau Literária: crítica e teoria de literaturas $\bullet$ seer.ufrgs.br/NauLiteraria

ISSN 1981-4526・PPG-LET-UFRGS • Porto Alegre • vol. 09, n. 01 • jan/jun 2013

Dossiê: Voz e Interculturalidade

\title{
A COMARCA ORAL SUL-MATO-GROSSENSE: UM ESTUDO COMPARATIVO ENTRE TAUNAY E SEREJO
}

\section{THE SUL-MATO-GROSSENSE ORAL COMMUNITY: A COMPARATIVE STUDY AMONG TAUNAY AND SEREJO}

Me. Mara Regina Pacheco (UEL/CAPES)

Resumo: Este artigo se propõe a analisar excertos da obra de Visconde de Taunay e do escritor sul-mato-grossense Hélio Serejo com o intuito de comprovar a existência da "comarca oral", defendida por Carlos Pacheco (1992), ideia na qual a oralidade é indicador cultural fundamental na ficção literária latino-americana. Na linguagem textual percebe-se a presença da cultura oral representativa da época histórica, bem como o indivíduo em suas práticas social, cultural e existencial. Muitos são os pontos que unem Taunay (1843-1899) e Serejo (1912-2007), apesar de terem vivido em séculos diferentes, os escritores tem em comum a construção romanesca e a representação do indivíduo local: o sertanejo (como mito), seu habitat, e suas práticas. A construção narrativa e posicionamento do narrador em questões como alteridade, focalização, tempo/espaço, exibem o traço historiográfico, o subjetivismo do "eu" lírico, o biografismo, o memorialismo do escritor romântico "portavoz", indicando a comarca oral local. Esses aspectos serão pontuados nos contos "O sertão e o sertanejo" de Taunay, e em "Caboclo de minha terra" e "Campeiro de minha terra", de Serejo.

Palavras-Chave: comarca oral; Romantismo; Visconde de Taunay; Hélio Serejo.

Abstract: This article aims to analyze excerpts from Visconde de Taunay and Hélio Serejo works in order to prove the existence of "oral community", defended by Carlos Pacheco (1992), idea in which orality is a fundamental cultural indicator in Latin American literary fiction. In textual language perceives the presence of the oral culture representative of the historical era, as well as individuals in their social, cultural and existential practices. There are many points that link Taunay (1843 - 1899) and Serejo (1912-2007), despite they have lived in different centuries, they have in common the Romanesque construction and representation of the local individual: the sertanejo (as a myth), their habitat, and their practices. The narrative construction and narrator focalization on issues like otherness, vision, time/space, which exhibit the historiographical trace, subjectivism of the lyric "I", the biographism, the memorialism of the romantic "spokesman" writer indicates the local oral county. These 
aspects will be scored in the short stories "O sertão e o sertanejo" by Taunay, and "Caboclo da minha terra", and "Campeiro da minha terra" by Serejo.

Key-words: Oral community; Romanticism; Visconde de Taunay; Hélio Serejo.

\section{Introdução:}

Este artigo apresenta as pesquisas iniciais do projeto "A comarca oral em Visconde de Taunay e Hélio Serejo" ", que tem como objetivo pesquisar nas narrativas desses escritores a presença da "comarca oral", tese de Carlos Pacheco (1992), que defende a ideia da ficcionalização da oralidade cultural na narrativa latino-americana. O envolvimento dos escritores na comunidade narrativa dos rincões do Mato Grosso (atual Mato Grosso do Sul), e na fronteira do Brasil com o Paraguai passou do ouvido que ouviu para a caneta que escreveu. Apesar de terem escrito em séculos diferentes, Taunay no século XIX e Serejo no século XX, ambos representam o mesmo espaço geofísico-cultural através de padrões estético-literários de base Romântica. Na diegese desses escritores verifica-se a presença da oralidade representativa da cultura, da origem, da identidade do povo fronteiriço, dos seus costumes e tradições.

Gonçalves Magalhães (In: MERQUIOR, 1997: 59), o precursor do romantismo no Brasil, afirma: "cada povo tem sua literatura própria, como cada homem seu caráter particular", e tanto Taunay quanto Serejo, deixam essas marcas do local nas suas construções romanescas. A maneira de fazê-lo é marcada de acordo com o contexto histórico vivido nos seus aspectos social, cultural, existencial. O historicismo é característico do romantismo na qual o escritor vê tudo em fluxo histórico. Eles historicizam e relativizam fenômenos momentâneos de determinado momento histórico. Não somente o interesse histórico se faz presente, mas também o arqueológico, etnográfico, e outros, que são fontes para o espírito romântico em busca do original, da primeva, do elementar, do arcaico, sempre direcionado à reintegração do seu "uno". O adensamento em busca dessa síntese é a alma romântica que prima pela revalorização do mito.

$\mathrm{Na}$ verdade, o mito torna-se, para eles (os românticos), um elemento fundamental de sua visão, uma das chaves que lhes parece dar acesso ao reino

\footnotetext{
${ }^{1}$ Este projeto vem sendo desenvolvido junto ao Programa de Pós-Graduação em Letras da Universidade Estadual de Londrina (UEL), em nível de doutorado financiado pela CAPES.
} 
do simples e do uno, onde não existem as fissuras e as complicações alienantes de uma consciência reflexa e fragmentária, de uma civilização que tudo dissocia e faz de tudo raciocínio (GUINSBURG, 1993: 282. grifo meu).

O mito é para os românticos a descomplicação, o contrário do racional, surge de uma criação que é inata, de uma inspiração que é intuitiva, espontânea. É o ímpeto da liberdade subjetiva da obra, que é um meio, e não um fim em si. É a expressão do "eu" que é estranho ao mundo, que sofre a "dor do mundo". Sentindo-se à margem, os românticos querem expressar a cultura dissociada, alienada, mas buscando, ao mesmo tempo, uma síntese integrativa. E eles o fazem através do mito.

O mito, nos dois escritores em estudo, aparece nos contos selecionados na figura do sertanejo. Ele é a representação dessa cor local, a caracterização do bom selvagem. É o toque da brasilidade na qual se firmou, segundo MERQUIOR (1977: 54), o nosso primeiro sistema literário, o Romantismo, não só dotado de consciência ideológica, como pragmática de uma "brasilidade". Essa firmação se deu por dois fatores: *uma nacionalização estética que valorizou particularidades (nacionais e regionais) e diversidades (tradição e evolução); *surgimento do romantismo junto com a fundação dos países latino-americanos. Novos países, novas necessidades de mitos para firmarem a origem das novas pátrias.

O folclore indígena toma o lugar dos mitos clássicos, e a criação folclórica nacional, mais popular, atende aos menos intelectuais. A nova plateia aceita versos mais curtos, o folhetim, as criações folclóricas, a subliteratura. E, o que mais interessa aos estudiosos da oralidade na literatura: "O enraizar-se do romantismo representou o triunfo da oralidade na literatura: o predomínio da experiência da palavra falada sobre o hábito sistemático da leitura reflexiva” (MERQUIOR, 1977: 55). Em uma época de pouca informação, muito analfabetismo, pouca intelectualidade, as criações nacionais acentuaram os verbalismos, as declamações, inspiradas nas fontes populares.

I. Guinsburg (1993:266-7) credita a fonte de criação do romântico à alma do povo: o folclore; e o homem em seu estado natural. Esse homem em seu estado natural, o ser íntegro e primitivo, o "bom selvagem" é caracterizado pela figura do sertanejo, nos dois escritores em estudo. O modo de representação desse mesmo sertanejo tem suas particularidades em Taunay (1843-1899) e em Serejo (1912-2007), onde se percebe ora aproximação, ora distanciamento, por parte dos narradores, em suas respectivas épocas históricas. Questões relativas à alteridade e à visão (focalização) do sertanejo são construídas, por eles, partindo-se do espaço 
e tempo que ocupam. Relevante se faz discutir três aspectos desta última afirmativa: alteridade; visão (focalização); espaço/tempo. A obra $O$ romantismo (1993), de I. Guinsburg colabora para o entendimento desses três pontos. Quanto à questão da construção por alteridade, o autor cita Schelegel:

Para alguém caracterizar alguém, alguma pessoa, precisa ser ele mesmo, isto é, a mesma pessoa e, apesar disso, outra. Isto significa que não é possível configurar outrem, sem se identificar com ele, pois do contrário não existirá objetividade para a caracterização (SCHELEGEL, In: GUINSBURG, 1993, p. 288).

$\mathrm{Na}$ tentativa de tentar captar um saber íntimo das coisas e dos seres, os românticos mergulhavam no individual e local descobrindo novos conteúdos, horizontes inexplorados, experimentavam, experienciavam, a fim de verificar, ou tentar estabelecer correspondências, afinidades. O conto de Taunay selecionado para essa análise evidencia muito claramente essa questão da construção por alteridade quando o narrador posiciona alternadamente o olhar do sertanejo e do viajante diante daquilo que vê. Quanto à questão da visão, Guinsburg escreve:

O "eu" é o construtor do mundo, ele o cria. Não se trata naturalmente de nosso "eu" pessoal, mas no íntimo de cada um de nós, de nosso "eu” psíquico, dinâmico, mais ou menos biográfico, há uma força espiritual, por assim dizer, comum a todos, que produz o mundo (GUINSBURG, 1993: 283).

Esse "eu" criador, o escritor porta-voz, o herói mediador, é munido de uma força natural: "o gênio original2". O foco, que antes, no Classicismo era no objeto criado, no Romantismo passa ao sujeito criador, no qual se coloca em primeiro plano tudo relativo a ele, caracterizando certo biografismo no qual a obra se confunde com o autor. $\mathrm{O}$ valor da obra passa a residir na expressão do íntimo do autor, na explosão de sua subjetividade. A criação torna-se recurso de comunicação da mensagem interior do escritor. No caso de Taunay e de Serejo, o memorialismo é intrínseco da escrita, uma vez que, muito do que criaram encontrou respaldo no vivido, no experienciado por eles (escritores) nos rincões do antigo Mato Grosso.

Em relação ao espaço/tempo, Guinsburg afirma que nos românticos existe um apurado senso de história, já que ela é um domínio no qual a sucessão dos fenômenos é altamente individual. Valoriza-se a alteridade, a diferença de um para com o outro, sua situação social, nacional, particular, peculiar. A concepção romântica reflete as diferenças entre os povos, suas especificidades, a contribuição de cada um no processo humano, as relações no contexto social e nacional, o indivíduo no seu habitat sócio-histórico (a cor local): “Trata-se, na

\footnotetext{
2 “O gênio original” é o conceito, as ideias, as aspirações do Romantismo (GUINSBURG, 1993: 267).
} 
verdade, de ver cada singularidade em seu contexto geral, cada ser humano na paisagem social que o forma e emoldura, relacionando-os por integração da parte no todo maior" (GUINSBURG, 1993: 269-70). O sertanejo é o ser singular, uno, ideal, emoldurado pela paisagem social da região fronteiriça do Brasil com o Paraguai, em Taunay e em Serejo.

A ficção construída pelos narradores taunayniano e serejiano possui o controle do tempo, posição e espaço em relação ao foco no qual há, tanto "seleção", como "combinação" de elementos no "fazer" ficcional. Wolfgang Iser acredita que tanto uma quanto a outra "turva" o mundo de referência. A "seleção" por criar redes de relações que deformam referências e promovem o crescimento das qualidades estéticas. A “combinação" por se tornar a matriz da qualidade estética (ISER, 1987: 220). Também a Lei do posicionamento, de Michael Holquist (apud. MACHADO, 1995), colabora no estudo quando afirma que o que vemos é governado pelo modo como vemos, e estes são determinados pelo lugar de onde vemos. Seleção, combinação, posicionamento são usados pelos escritores ao configurarem suas narrativas. Como cada um o faz usando, a mesma base romântica, a sua subjetividade autoral (tão cara aos românticos), no seu espaço/tempo de séculos diferentes?

Há uma variedade de focalizações possíveis "entre a mente que percebe e a coisa percebida". Como Taunay, descendente de estrangeiros, escritor com título de "Visconde", com formação acadêmica de engenheiro geógrafo, bacharel em ciências físicas e matemáticas, professor de diversas disciplinas (francês, geologia, botânica), e Serejo, um nativo da região, nascido em Nioaque/MS, neto de coronel do exército brasileiro, filho de dono de terras, focalizam o sertanejo? Há diferenças e/ou semelhanças na ficcionalização da comarca oral local nos diferentes séculos nos escritores?

Os contos de ambos os escritores apresentam as práticas cotidianas da região, que podem ser observadas através dos diálogos culturais, preservadores da memória, da tradição, da identidade cultural do povo fronteiriço. No entanto, cada escritor ficcionaliza o discurso a seu modo e ponto de vista particular. A voz desse discurso é envolta por signos e práticas que estabelecem a experiência e a representação do histórico, social, cultural do povo fronteiriço. Pela observação do cotidiano representado é possível identificar uma voz, um discurso que surge da "comarca oral" através da ficcionalização da realidade local. A "realidade" que surge do discurso produzido pelo relacionamento do indivíduo com seu mundo. Esse mundo descrito, e suas práticas, refletem a "comarca oral" da tese pachequiana. Carlos Pacheco 
(1992) afirma que características de uma cultura predominantemente oral podem ser encontradas nas narrativas de alguns escritores pelo seu "modo de fazer". O estudioso defende uma invenção da ficcionalização da oralidade na literatura, o que demarcaria a existência da "comarca oral". Pacheco argumenta que a representação ficcional de uma realidade local/regional tem sido uma tradição nas letras latino-americanas, como Grande sertão: veredas. Assim como Rosa, Taunay e Serejo ficcionalizam a memória pertencente a uma determinada comunidade: antigo Mato Grosso, atual Mato Grosso do Sul, na fronteira do Brasil com o Paraguai. A narrativa ficcionalizada configura valores culturais guaranis, paraguaios, e brasileiros carregados da oralidade da qual fala Pacheco em La comarca oral (1992), e característica do romantismo, segundo a defesa de Merquior (1977), aqui já anteriormente apresentada. As narrativas imprimem marcas da memória coletiva cultural oral de um locus específico, transmitido da sabedoria popular, antes oral. Tendo em mente as premissas acima apresentadas observar-se-á como cada um dos escritores configura o mito: o sertanejo, e sua oralidade.

\section{Visconde de Taunay (1843-1899)}

Em Céos e terras do Brasil (TAUNAY, 1930), encontramos a sugestiva afirmativa prefaciada: "poucos conheceram a natureza brasileira como o Visconde de Taunay e muito poucos a observaram com igual enlevo". Os termos "poucos" e "igual" usado na frase remetem de imediato às questões de unidade e pureza: o olhar europeu "vê correto e melhor". Uma das características dos românticos abordada por Merquior, da visão, da focalização, bem como do posicionamento de Holquist, é de um narrador que vê e registra o que vê de um lugar marcado: ora perto, ora distante.

O conto, escrito quando Taunay desbravava o antigo Mato Grosso, atual Mato Grosso do Sul, evidencia a característica viajante do autor, no qual, por alteridade, se constrói o "eu" frente o "outro": o "eu", o viajante, "aquele que sabe", de um lado; e o "outro", o sertanejo nativo, aquele que "não sabe". O conto, em toda a sua extensão, apresenta as visões do viajante e do sertanejo, alternadamente. Outra característica romântica creditada aos românticos por Merquior. O viajante, ao descrever as "pindahybas", "buritys" e os "coqueiraes", o faz com grande ênfase, exibindo encantamento diante do "novo", e paralelamente, deixa vazar a visão do sertanejo, diante da mesma cena, algo comum descrito como "amontoados de compactos massiços", blocos de matéria bruta (sertanejo) versus escultura de Rodin (viajante). Perceba o primeiro caso com o trecho: "Enfileirão-se ás vezes 
as palmeiras com singular regularidade na altura e conformação; mas não raro se amontoão em compactos massiços" (TUANAY, 1930: 20). E o segundo:

Como são belas aquelas palmeiras! O estipite liso, pardacento, sem manchas mais que pontuadas estrias, sustenta denso feixe de peciolos longos, e canulados, em que assentam flabelas abertas como um leque, cujas pontas se acurvam, flexiveis e tremulantes. Na base, e em torno da coma, pendem, amparados por largos spathos, densos cachos de cocos tão duros que a casca luzidia, revestida de escamas rhomboidaes e de um amarelo alaranjado, desafia, por algum tempo, o ferreo bico das araras (TAUNAY: 1930, p. 21).

As descrições das visões do primeiro e do segundo caso são criadas de modo a evidenciar uma enorme distancia entre os dois (posicionamento). Isso vai variar no conto no momento inicial (distanciamento), meio (mudança de percurso narrativo), e final (maior proximidade), em relação à representação daquilo que vê: a floresta de pindaíbas e buritis e o seu entorno. $\mathrm{O}$ sertanejo enxerga amontoados de compactos maciços das palmeiras locais. $\mathrm{O}$ narrador viajante vê tudo com lentes de aumento, com detalhes minuciosos, de nomenclaturas da flora, em botânica ${ }^{3}$, bem como um cuidadoso e apurado trato ao descrever o que vê. Maria Lídia Lichtscheidl Maretti, em sua tese "Um polígrafo contumaz" - O Visconde de Taunay e os fios da memória, afirma: "o traço viajante-com-olhos-de-pintor do narrador, essencial para a composição da brasilidade tradicional romântica" (1996, p. 65). O traço escritor/pintor é bastante evidenciado devido à acurada efusão de cores que figura no conto todo: "Juntam-se elas em grupos, umas vermelhas como chispas soltas de intensa labareda, outras versicolores, outras pelo contrario de todo azues, de maior viso e que por parecerem em distancia, negras, têm o nome de araraúnas" (TAUNAY, 1930, p. 22. grifo meu). A construção narrativa da visão do viajante, que passeia por quase todos os tons da palheta, é construída para o sertanejo como sendo causa de marasmo e apatia: "Vê tudo aquilo o sertanejo com o olhar carregado de sono" (TAUNAY, 1930, p. 22). O que é representado como comum e apático para o sertanejo é representado como diverso e extravagante para o viajante. Enquanto para o primeiro o cenário inspira paz e tranquilidade por fazer parte do seu mundo, para o último desperta curiosidade e deslumbramento por não ser natural a si. Até esse ponto do conto, o diferente inebria positivamente, porém, ao cair da noite, o desconhecido faz aflorar medo no "astuto" viajante que passa a se sentir se inseguro e receoso

\footnotetext{
${ }^{3}$ Visconde de Taunay acumulava especialidades de conhecimento. Foi militar, engenheiro, político, geógrafo, minerólogo, botânico, dramaturgo, crítico teatral, escritor, entre outros.
} 
dos ruídos e dos insetos desconhecidos fazendo-o "crear mil fantasias": "Qualquer ruído nos causa sobressalto; ora o grito alegre do zabelê nas matas, ora as plangentes notas do bacurão a cruzar os ares" (TAUNAY, 1930, p. 23). O anoitecer ilumina os medos do viajante a ponto de fantasiar "máu grado" na ausência da luz. O diferente, que antes seduzia o viajante, leva-o ao medo. A noite que causa angústia ao viajante faz com que o sertanejo "sinta-se deveras feliz. Nada lhe perturba a paz do espírito ou o bem estar do corpo" (TAUNAY, 1930, p. 24). Esse percurso de construção por alteridade e distanciamento salienta também a identificação do personagem romântico com seu habitat, integrado ao seu meio (sertanejo), e o que está fora dele (viajante). $\mathrm{O}$ mesmo cair da noite que expõe as inseguranças do viajante, traz à tona a força e sabedoria do sertanejo e marca a sua comarca oral:

A certeza que tem de que nunca poderá perderse na vastidão, como que o liberta da obsessão do desconhecido, o exalta e lhe dá fóros de infalibilidade. Se estende o braço, aponta com segurança no espaço e declara, peremptoriamente: - Neste rumo daqui a vinte leguas fica o espigão mestre de uma serra braba, depois um rio grosso; dalli a cinco leguas outro mato sujo que vai findar n'um brejal. Se vassuncê frechar direitinho assim umas duas horas, topa com o pouso do Tatu, no caminho que vai a Cuyabá. O que faz n'uma direcção, com a mesma imperturbavel serenidade e firmeza indica em qualquer outra. A unica interrupção que aos outros consente, quando conta os innumeros descobrimentos, é a da admiração. A minima suspeita de duvida ou pouco caso, incendem-se-lhe de colera as faces, e o gesto denuncia indignação. Vassuncê não credita! protesta então com calor. Pois ensilhe o seu bicho e caminhe como eu lhe disser. Mas assumpte bem, que no terceiro dia de viagem ficará decidido quem é cavoqueiro e embromador. Uma cousa é mapiar á toa, outra andar com tento por estes mundos de Christo. (TAUNAY, 1930, p. 27).

Esse trecho evidencia a diferença do discurso projetado pelo narrador viajante e o sertanejo. O viajante, erudito na arte (das cores e das formas), apresentou através da sua narrativa a sua comarca oral de ancestralidade europeia (una e pura), de porta-voz real ${ }^{4}$, marcando seu posicionamento. O sertanejo é também representado em seu in natura, por meio, inclusive, da lacuna metonímica no trecho acima transcrito, demarcando ipsi literis a sua comarca oral latino-americana (cabocla) nos vocábulos em itálico: braba, vassuncê, credita, assumpte, cavoqueiro, embromador, mapiar. Essa construção narrativa feita pelo narrador taunayniano cria distancia entre os dois discursos: europeu (viajante) e latinoamericano (sertanejo). No entanto, quando é dada a permissão da fala ao sertanejo ele mostra seu conhecimento adquirido pela experiência - o "saber fazer" de Michel de Certeau (2003) -

\footnotetext{
${ }^{4} \mathrm{O}$ visconde de Taunay viajava com o Exército, como relator, a pedido de D. Pedro II.
} 
sabedoria conquistada através da prática cotidiana do homem que enfrenta a vida e aprende com ela no "fazer". O sertanejo, com sua sabedoria adquirida pelo "fazer", quando aponta para uma direção e dá a distância de um ponto a outro é porque "sabe" através da prática. Esse "saber", em loco, saber oriundo do seu habitat, segundo o texto, apenas permite ser contestado e interrompido caso o interlocutor queira expressar admiração pelo conhecimento daquele que fala. A valorização do "saber" se dá pelo que é experienciado e vivenciado, como é possível verificar no trecho abaixo:

Enquanto moço, o seu unico fim é devassar terras, pisar campos onde ninguem antes puzera pé, vadear rios desconhecidos, despontar cabeceiras e furar matas, que descobridor algum até então varara. Cresce-lhe o orgulho na razão da extensão e importancia das viagens emprehendidas, e cifra-se seu maior posto em enumerar as correntes caudaes que transpoz, os ribeirões que baptisou, as serras que transmontou e os pantanaes que afoutamente cortou, quando não levou dias e dias a rodea-los com rara paciencia. Cada ano que finda lhe traz mais um valioso conhecimento e acrescenta uma pedra ao monumento da sua inocente vaidade. - Ninguem pode comigo, exclama ele emphaticamente. Nos campos da Vaccaria, no sertão do Mimoso e nos pantános do Pequery, sou rei. E esta presumpção de realeza infunde-lhe certo modo de falar e de gesticular magestatico em sua singela manifestação. (TAUNAY, 1930, p. 26, 27)

O sertanejo é rei da experiência que carrega, do conhecimento adquiro na prática ao “fazer". É segundo o texto, uma "vaidade inocente", que não foi adquirida nos bancos acadêmicos (em oposição ao vouyer). No entanto, apesar dessa "inocente vaidade", o sertanejo taunayniano é construído com traços de "presumpção de realeza", e com "gesticular magestático". Tem marcas do "eu" do escritor, de biografismo, do escritor porta-voz do Rei. É um narrador posicionado que marca a comarca oral da qual pertence, e da qual quer representar com seus traços próprios e também alheios. Como é construído, então, o sertanejo serejiano? Vejamos!

\section{Hélio Serejo (1912-2007)}

Nos contos "Caboclo de minha terra" (SEREJO, 2008, v. II, p. 151-153), e "Campeiro de minha terra" (SEREJO, 2008, v. IV, p. 77-91), encontramos a representação do sertanejo por Serejo. Se o sertanejo taunayniano é construído com características tomadas da realeza, condizente com o momento histórico, o sertanejo serejiano, em ambos os contos, também historicizado, tem as características de herói de guerra (da Tríplice Aliança, que ocorreu nas 
fronteiras do Brasil/Paraguai, entre 1864-1870). O avô de Serejo, Coronel Francisco Marcos Tury Serejo, lutou na guerra, a mesma na qual participou Taunay como relator, a pedido do Rei. Essa experiência rendeu a Taunay inspiração para a escritura das reconhecidas obras Retirada da Laguna e Inocência, e muitas outras não tão conhecidas do público. À semelhança de Taunay, Serejo também relata em suas obras conteúdo relativo a essa guerra. Hildebrando Campestrini em O trilhador de todos os caminhos (SEREJO, 2008, p. 19), fala do curioso Hélio Serejo, ainda menino, que sempre acompanhando o avô e o pai, ouvindo-os atentamente e registrando tudo em cadernos, que chegou ao número de sessenta e quatro ${ }^{5}$. $\mathrm{O}$ fato é que credita-se muito do que escreveu a esses cadernos (memórias). Da memória do ouvir e do contar dos seus precursores, Serejo assim refere-se ao sertanejo/campeiro/caboclo: "Você é um bravo... um colosso, campeiro de Mato Grosso! Seu destino... é a sua glória! Você é marco da história!” (SEREJO, 2008, v. IV, p. 91). Nesse contexto Serejo exalta a figura do sertanejo que na guerra da Tríplice Aliança, ajudou "o irmão astuto a povoar os pagos da terra virgem a ser domada" (p. 91). Ou seja, o sertanejo nativo "índio buenaço... alegrão - imagem de meu sertão" ganha traço de "estoico guerreiro" (p. 77-8), já que por ser conhecedor nato daquelas paragens remotas, "Por ser um campeiro conhece o chão da querença” (p. 82), "conhece os ditos e mitos da tradição" (p. 84), pode ajudar com eficiência o indivíduo de fora, não conhecedor da região, a desbravar aquele espaço. A representação do sertanejo aqui é de um sertanejo mártir: "Tu és a verdadeira sentinela de mármore da minha terra. Teu passado é um livro aberto, cheio de exemplos dignificantes para as gerações do futuro" (SEREJO, 2008, v. II, p. 151). O conto apresenta um sertanejo que respondeu ao pedido de auxílio da pátria diante do recrutamento de homens na guerra. É um sertanejo contextualizado historicamente:

Quando o coronel Camisão, o grande Carlos de Morais Camisão, necessitou de um homem para seu ordenança, que "tivesse a destreza da onça parida de novo e os pulsos fortes como a aroeira", foi de ti que recaiu a escolha. Quando o heroico bandeirante Antônio Dias, tipo materializado do desbravador audaz, compreendeu que com os tímidos negros de São Paulo e com os sisudos goianos nada faria e dificilmente chegaria ao Eldorado, mandou parar as pirogas, e foi à tua procura; tu vieste, caboclo macanudo, satisfeito e sem ambição, auxiliar o paulista amigo que vinha trazer o progresso para a nossa terra. E, com a tua ajuda, a bandeira triunfou. (SEREJO, 2008, v. II, p. 152).

\footnotetext{
${ }^{5}$ Campestrini coloca em nota de rodapé que não se tem notícia destes cadernos e que nada a respeito foi encontrado após sua morte.
} 
O narrador serejiano credita ao sertanejo a vitória da guerra da Tríplice Aliança ${ }^{6}$, uma vez que o seu conhecimento da região fez toda a diferença para a empreitada ter sucesso. Este era o mito, o homem ideal, íntegro, o "bom selvagem" do período histórico de Serejo. O habitat inóspito do sertanejo foi, em certo momento, trincheira de guerra. Há no conto uma focalização espaço/temporal romântica, uma seleção e combinação dos elementos no fazer ficcional do escritor que aponta um evento marco, que foi o episódio da Retirada da Laguna:

Em Laguna, nessa trágica mas gloriosa retirada, quando o cólera-mórbus atacou a tropa, tu, caboclo de sangue íncola, ajudaste a transportar na padiola centenas de voluntários coléricos. Mais ambientado, era sempre o último que curvava os joelhos e beijava a terra úmida (SEREJO, 2008, v. II, p. 152).

O narrador conta de um momento histórico no qual o sertanejo, adaptado ao ambiente inóspito "não tombava", não morria acometido pelas doenças silvícolas, era mais resistente, mais aclimatado, e assim muito serviu e colaborou com a Pátria. Em meio à narração romantizada de enaltecimento do herói regional representa-se, conjuntamente, as doenças que acometiam o povo da região, bem como características das personalidades requeridas pelo ambiente silvícola, isso tudo dentro da forma romântica de criação na qual a calma, a docilidade, a bondade sertaneja rapidamente se transformava em valentia e coragem se necessário fosse:

Não há ninguém que se lhe compara em nobreza e bondade, em abnegação e heroísmo. Se há necessidade de ser dócil como a pomba-rola, ele é; se, porém, o momento exige arrojo e bravura, o caboclo se transforma num segundo, tornando-se feroz e agressivo como o jaguar acuado (SEREJO, 2008, v. II, p. 151).

Um sujeito adaptável, que era moldado através das suas práticas cotidianas de desbravamento, de sobrevivência, seja nos ervais nativos, seja nas querências perdidas, seja no fronte de guerra. A narrativa serejiana imprime a idealização de um herói de guerra de uma região circunscrita, de uma comuna oral fronteiriça registrada pelo escritor no conto. A própria forma do conto vem do oral: uma ode declamatória de exaltação, típica dos povos agrafos. Nela exalta-se o mito do herói de guerra. Uma guerra específica, a Tríplice Aliança,

\footnotetext{
${ }^{6} \mathrm{O}$ saldo de mortos paraguaios chegou $15 \%$ a $20 \%$ da população; o exército brasileiro perdeu 50 mil soldados; os combatentes argentinos abatidos foram $18 \mathrm{mil}$; já as forças uruguaias de 5.600 homens, terminaram com 2500 .
} 
que ocorreu numa região demarcada, a fronteira do Brasil com o Paraguai, que exigiu contingente humano local: o sertanejo.

A lacuna metonímica usada por Taunay ao representar a voz do sertanejo não aparece nos contos de Serejo aqui selecionados (apesar do escritor o fazer em outras obras), porém, algumas expressões como "índio buenaço", "chão da querença", "caboclo macanudo", e a conjugação frequente com o uso do pronome "Tu", dão indícios das nuanças do hibridismo de culturas diaspóricas que subiram da região sul do país para o centro-oeste, demarcando desse modo o momento histórico e as marcas da comarca oral da referida fronteira naquele tempo/espaço.

\section{Conclusão:}

A representação do mito local: o sertanejo é construído tanto por Taunay, quanto por Serejo, com características românticas. A criação de cada um traz traços subjetivos, certo biografismo, memorialismo e historicismo comum aos românticos. Cada um dá a seu mito as características do seu tempo/espaço. Com Taunay, o sertanejo ganha ares majestáticos, com Serejo ares de mártir. Em ambos perceberam-se as marcações da realidade do indivíduo nos seus aspectos social, cultural, existencial, demarcando assim a comarca oral ficcionalizada de uma determinada região: a fronteira do Brasil com o Paraguai, em solo do antigo Mato Grosso, nos dois séculos XIX e XX.

Quanto à comarca oral, Taunay destaca o falar popular local fazendo uso da lacuna metonímica e marcando tais palavras em itálico no texto. Já no caso dos dois contos de Serejo aqui analisados esse artifício não chega a ser usado (apesar do escritor o fazer em outras obras), a oralidade é evidenciada (além das evidencias socioculturais temporais relatadas), pelo uso de verbetes (apontados anteriormente), que expressam a mistura por hibridismo da fala dos indivíduos diaspóricos (do sul do país) com os sujeitos locais da região supracitada.

Ainda em relação à construção narrativa, no caso de Taunay, o uso da alteridade proporciona ora distanciamento, ora proximidade com o mito local, criando um jogo de focalização alternada entre o viajante e o sertanejo, fazendo-se pensar o "outro" e suas relações de poder e conhecimento. Já a narrativa serejiana não chega a confrontar o herói de guerra, não faz o jogo opressor versus oprimido. O discurso é pautado na conformação do mito, nas primícias românticas, sem confronto, sem enfrentamentos. Serejo exalta o elemento 
local, o condecora, volta o olhar para aquele que "faz", na sua região: o herói caboclo local. No entanto, mesmo tendo escrito quase um século após Taunay, Serejo não supera, não avança, não dá um salto adiante em relação à tradição, mantendo na sua escrita o princípio romanesco das odes e exaltações heroicas do século anterior.

\section{Referências:}

CERTEAU, Michel de. A invenção do cotidiano. 1. Artes de fazer. 9.a edição. Petrópolis/RJ: Editora Vozes, 2003.

GUINSBURG, I. O romantismo. São Paulo: Perspectiva, 1993.

ISER, W. O fictício e o Imaginário: Perspectivas de uma Antropologia Literária. Trad. Johannes Khetschmer. Rio de Janeiro: Editora da UERJ, 1996.

MACHADO, Irene A. O romance e a voz. A prosaica dialógica de Mikhail Bakhtin. São Paulo: Imago/FAPESP, 1995.

MARETTI, Maria Lídia Lichtscheidl. "Um polígrafo contumaz" - O Visconde de Taunay e os fios da memória. Tese de doutorado apresentada ao Departamento de Teoria Literária do Instituto de Estudos da Linguagem da Universidade Estadual de Campinas. Campinas/SP: 1996.

MERQUIOR, José Guilherme. De Anchieta a Euclides. José Olímpio: 1977.

PACHECO, Carlos. La comarca oral. Caracas: Ediciones La Casa de Bello, 1992.

SEREJO, Hélio. Obras completas. Hélio Serejo (org.). Hildebrando Campestrini. Campo Grande/MS: Instituto de História e Geografia de Mato Grosso do Sul, 2008.

TAUNAY, Visconde. Ceos e terras do Brasil. 7.a ed.. Rio de Janeiro/Belo Horizonte: Livraria Francisco Alves, 1930. Brasiliana Digital/USP. 